\title{
Prototyping as Event: Designing the Future of Obesity
}

\begin{abstract}
This paper takes up the notion of event to explore the practice of prototyping in design as a relational process generative of multiple becomings. The paper outlines a case involving a team of user-centered designers as they envision, construct and demonstrate a wearable technology to intervene in public health warnings concerning obesity. The paper examines various co-becomings of users and technology through the course of a two-stage development cycle and employs the heuristic distinction between 'distal' and 'proximal' users as means to examine the different definitions of obesity occasioned therein. The term inventive risk discourse' is coined to describe the designers' articulation of the problem space of obesity as a future figuring putative users. Examples of proximal users are then discussed as users involved in the various enactments of the prototype system as it is programmed and assembled in the present. The implications of this are discussed in terms of the specific definitions of obesity that concrese around particular prototype-user assemblages as well as indicators of overspill that often exceed normative accounts. In conclusion, I consider the case as a rough cosmopolitical sketch where designers engage obesity science as inventive problem making where multiple empirical variations of obesity emerge.
\end{abstract}

Keywords: prototype, event, design, becoming, obesity

\section{Introduction}

According to mainstream 'obesity science' as well as national and international public health agencies, the world is currently in the grip of an obesity epidemic, a disease said to be present in and imminent to large swathes of national and global populations. For advocates of fat intervention, being overweight is preventable and manageable by bringing about a change in peoples' lifestyle choices and behaviour, particularly through diet and exercise. Despite the moral panic stirred up by medical science, governmental policy, media hype, obesity campaigners as well as commercial actors the social and scientific facticity of the epidemic remains highly contested by scientists, activists and commentators alike (Saguy and Almeling, 2008, Campos et al., 2006, Saguy and Riley, 2005). Arguably, the event that sparked the framing of the epidemic was the publication of the World Health Organisation's (WHO, 2000) report 'Obesity: Preventing and Managing the Global Epidemic' that occasioned obesity as a standardized global health risk, and its reception by various government health agencies, including the U.S. Department of Health and Human Services $(2001,2000)$ and the UK Government Office for Science (Butland et al., 2007). The biopolitical linkages constructed between individuals and populations that ensued in health policy served to 
activate new actors in the obesity controversy, including those who view the market potential of epidemic as a correctable health problem. ${ }^{1}$

In what follows, I take up the notion of event to explore the prototyping practices of a team of designers, working on behalf of a U.S. based multinational IT corporation, as they engage in designing a body-worn technology to support individuals' prevention and management of obesity and as such, seek to prospect the epidemic as a viable microprocessor market. Throughout this paper, I will argue that prototyping is emblematic of the importance of refusing to make an artificial distinction between prototyping and the prototype, of designing and thinking about design. In doing so, I will develop the approach of foundational studies of science, technology and society, and in particular the sociology of innovation, which have firmly established the view that putative users and technology co-become during the prototyping of an emerging technology (Akrich, 1992a, Callon, 1986, Woolgar, 1991, Kline and Pinch, 1996, Oudshoorn and Pinch, 2003). In this view, both users and prototype are mutually defined and, in the process, define the collective producing the prototype-user and delineate the collective proceeded by the innovation (Akrich et al., 2002). By explicitly taking up the concept of event, as a becoming together of multiple elements, to think through the practice of prototyping in empirical detail, what becomes apparent is the multiplicity of users that both resource and get defined during design. The iterative process of designing a technology is noticeably awash with users in various guises, not least those who resource system requirements and specification, those who are inscribed into the artefact, future representations that undergo definition and redefinition as well as othered non-users (Wyatt, 2003, Akrich, 1992b, p. 209). The upshot, for the case in hand, is that various user assemblages (Wilkie, 2010) of patient-technology-disease emerge during prototyping, defining the disease, figuring the putative patient as well as proposing future medico-technological healthcare provision and markets made visibly and materially manifest through prototyping. What is distinctive about the eventfulness of prototyping, and missing from other performative accounts of the practice, are the empirical and concrete variations that operate in the present to grasp, anticipate and enact the future, in the present. In short, prototyping in design entails a material orientation to multiple, open and indeterminate healthcare propositions.

\section{Prototyping in Design}

Before moving onto the case in hand, I will first outline the role of prototypes as devices for resourcing system design. Prototypes have and continue to play a significant role in design practices variously predicated on user-involvement. ${ }^{2}$ Broadly put, prototypes act as sociomaterial mediators during negotiations between designers and users in order to bring systems into being. According to the literature, there are various approaches to prototyping in design and Bødker and Grønbæk (1991, p. 198) provide a fitting fourfold typology. First, designers 
employ prototyping to evaluate and adjust the specifications of a system under development. Second, complete prototypes provide a full and materially formal description of what a future system will do. Third, exploratory prototypes are rapidly made and disposable mock-ups that aid the clarification of system requirements. Lastly, cooperative prototypes mediate the capacity of both users and designers to define and negotiate system requirements. This approach closely associated with Scandinavian 'Participatory Design' (Ehn, 1988, Ehn and Kyng, 1991) challenges the view that workplace technology and information systems, more generally, should be solely designed by expert designers. As such, in the design of information systems, prototypes act as both literary devices, where system specifications are abstractly described, and as socio-material configurations that embody existing and future practices in durable artefacts (Suchman et al., 2002, p. 166).

Here, it is also worth noting Suchman's et al.'s (ibid. ) view of prototyping, one which is premised on an ethnomethodological approach to technology design and the reconfiguration of situated workplace practices. In their account of the design of a document storage and retrieval system for the designers of a bridge, a collaboration between Xerox PARC and the U.S. Department of Highways, the authors describe prototyping as the production of a contingent and yet durable achievement that worked to recognisably reconstruct existing practices whilst operating as a means to bring new civil engineering practices into being. ${ }^{3}$ Viewing the prototype as an exemplar of a performative device, Suchman et al. describe how the document retrieval prototype acts as part of a 'dynamic assemblage of interests, fantasies and practical actions, out of which new socio-material arrangements arise' (ibid. , p. 175). Here, the prototype is viewed as a 'multivocal' and 'reflexive probe' that embodies multiple accountabilities: an artefact that aligns and can be aligned to multiple interests including those involved in research, product innovation, marketing and publicity as well as incorporation into working practices.

One upshot of this account of prototyping concerns the way in which the multiplicity of technoscientific objects are conceived as singularities and they way in which interests and actors are mutually defined, or become, during the process of prototyping. More specifically, the case of the document retrieval system demonstrates how diverse and multiple interests are aligned and can be addressed by the prototype. Now, a focus on event, as I will describe next, proposes that interests are not simply pre-given entities to be incorporated into durable multiperspective objects (Star and Griesemer, 1989) during the practices of technological design, but instead, can be generated (Law and Callon, 1992, p. 25) alongside objects that are enacted anew in the process of prototyping.

Danholt's (2005) case study of the development of a disease management technology provides another performative account where prototyping is viewed as a 'mutually transforming' 
activity where novel forms of patient subjectivity are brought into being alongside the artefact under development. Such a perspective foregrounds a consideration of the ontological politics of user-centered design (Berg, 1998, Garrety and Badham, 2004) where design, and the practice of prototyping more specifically, are oriented towards proposing novel bodies with new capacities and competencies, or as $\operatorname{Mol}(1999$, p. 75) puts it, new realities. In the case of the diabetes management technology, patients emerge as complex actors who are at once capable and incapable, dedicated and resistance as well as bemused. Notably, Danholt elaborates on 'vectors of becoming', importing it from Stengers' (2000, p. 154) discussion of the specificity of scientific practice to a conceptualisation of design practice. ${ }^{4}$ In doing so, Danholt argues that prototyping, as a mutually transforming procedure is also an affective process that produces simultaneity such as artefacts and users, existence and knowledge. Furthermore, it is an interested and located practice where its outcomes are never abstract but always concretely indexical (Garfinkel, 1967). As I will show in the case study that follows, this understanding of prototyping is instructive in understanding how obesity is never abstract but always concrete and specific and always actualised in the specificity of an event.

The sociology of expectations provides another way to understand the performativity of prototypes (Wilkie, 2010, p. 142). ${ }^{5}$ One particularly salient aspect of prototypes is their capacity to reify the future in present - not least in the coding of future practices. As sociomaterial artefacts that are indexical to designer-user relations, prototypes operate as experiments to durably translate and transform the interests of implicated actors. As such, prototyping can be viewed as the local and material enactment of a future system design in the present, wherein users are mobilised in the design process as either active 'creative' actors or as passive instruments for system evaluation. Accordingly, as expectational devices, prototypes function to materially envision and construct the future in the present, which in turn work to bring about a future in the present (cf. Michael, 2000, p. 22). As a future-making practice deployed as part of organisational techniques tasked with technological design, prototyping can be set alongside other formal methods for managing and coordinating uncertainty, such as Foresight, risk analysis and DELPHI (De Laat, 2000). Thus, design practice can also be viewed as means for prospecting sociotechnical futures coextensive with other technoscientific sites and fields of anticipation (c.f. Adams et al., 2009).

In sum, prototyping, viewed through the lens of performativity, provides a means of sensitising the present study to a more relational and process oriented view of design practices. ${ }^{6}$ The implications of this can be understood through the multiplicity of simultaneous orderings and disorderings in the concrescence of a prototype. In what follows I sketch out how the notion of event might be used to further explore and nuance this processual view. 


\section{Event and Becoming}

What is an Event?7 To answer this question I turn to the work of Whitehead, Stengers and Fraser, to illuminate a particular understanding of the practice of prototyping as a process of becoming and individuation. In doing so, I aim to avoid what Whitehead labelled 'bifurcated' reductions to dualisms such as subject and object, or in this case, user and device - a bifurcation which, incidentally, still underpins the practice of user-centred design (Wilkie, 2010, Berg, 1998). The notion of event denotes a process where multiple and diverse elements, or prehensions to be precise, come together and in coming together change one another and themselves. It is through the process of actualisation that entities acquire a specific identity and set of capabilities. Hence, Whitehead's need for the term prehension to describe the way novel entities come into being. Furthermore, their being is instantiated via the specificity of their becoming: "how an actual entity becomes constitutes what that actual entity is... Its "being" is constituted by its "becoming". This is the "principle of process" (Whitehead, 1978, p. 23. Emphasis in original). The notion of event therefore denotes a view of entities as relational bodies where heterogeneous elements combine in a process of unification. Thus, concrete and actual things, such as prototypes, users and designers are viewed not as objects and subjects, but rather as processes that undergo continual unification and change. Out of such unities individuated technologies and users can arise by way of the bifurcation processes of usercentered design, where, for example, users inform system specification or how a technology modifies the practices of users. They may also be present within such an event's abstractions, namely design discourses, which articulate the event in terms of bifurcation.

For Stengers (2005b, p. 147), events can be understood by way of three characteristics, or 'conditions', that are apparent in and illuminate the role of prototyping in design. ${ }^{8}$ First, prototypes occasion 'nonsymmetry' between a past and a present: they propose the occasioning of new sociotechnical arrangements, not least body-technology configurations, healthcare markets as well as disease management and prevention techniques. Second, as explorative devices, prototypes are indeterminate in so much as the outcome of prototyping practices cannot be known in advance. Here, the specificity of public health intervention by way of a concrete proposal for a mass-produced technology-user assemblage is yet to be determined. Third, prototypes mark a difference between a before and an after that matters. That is to say, an event brings about new practices, knowledge and orientation to problems, for example when an empty cardboard box is transformed into a mock-up of a 'desktop laser printer' to materially re-imagine and reconfigure the proofing practices of and shop floor relations between typographers, journalists, trade union representatives and management (Ehn and Kyng, 1991) or, as in this case, when obesity becomes identifiable and calculable through body-mass indices leading to new modes of healthcare practice and governmental 
population management. Thus, what signals an event are novel ways in which entities relate to themselves and their environment. This is an important aspect of process since if everything can be regarded as process, how does the analyst identify and demarcate a significant event for scrutiny? On a methodological note, the notion of event provides a way to understand how prototyping brings about new forms of patient subjectivity in relation to new forms of obesity. Analytically, this means being attentive to the differences that are made to matter in prototyping. This also points to the 'event' of deploying the concept of the event, where the cardboard mock-up is re-specified as illustrative of prototyping as a process of becoming.

Stengers (2000, p. 98) makes a crucial point about the diversity of entities that undergo becoming in an event. In brief, it is their very variety and density that strengthens the durability of an actualised entity. Thus, the efficacy of prototyping can be understood to rely on the increasing heterogeneity of a process, by, for example, mobilising statistical health discourse, enrolling novel technological platforms such as activity sensing devices and algorithmic 'intelligence', engaging a discursive register within HCI as well as widening the heterogeneity of implicated users. This corresponds with the interest model of innovation as network building that constitutes the strength and stability and hence reality of technoscientific objects (Akrich et al., 2002: 205). Here, prototyping not only concerns bringing a technology into being but also defining the geometry of the very collective that is producing and proceeded by the innovation. It also provides a way out of the predicament of discovery - whether or not an entity existed prior to its discovery - where the 'event' of the WHO report (2000) can be said to have transformed obesity into a pandemic. Arguably, the publication and reception of the report changed the historicity of being obese and as such, the notion can be understood as a way of thinking about the dynamic and contingent specificity of prototyped entities that emerge to address the disease in design practice.

Another important aspect of the notion of event is its scope. Here, Stengers (2000, p. 66) argues that it is impossible to account for all the entities implicated in an event since it is through the event that entities gain definition. As such there is always excess or overflow (Mackenzie, 2005, p. 391) to an event outside which provides it with an immanence or the potential to become something new or different. That is to say, technoscientific objects, and prototypes in particular, are generative and open to ongoing transformation: they have an immanence that cannot be wholly captured or defined by those involved in its becoming nor by the analyst or ethnographer of such objects. Here, the relation between the actual and the potential comes to the fore as that which is immanent to a sociotechnical concrescence. In this sense, prototypes are prime examples of what Whitehead (1978, pp. 185-186) calls propositions which he defines as a "hybrid between pure potentialities and actualities". Thus, a defining characteristic of becoming entailed in the event is the production of virtual relations 
that may or may not be apprehended but still 'entertain' subsequent change. For Whitehead, propositions can be 'conformal' and support existing relations, or they can be 'non-conformal' and thus bring about a novel or creative change. Propositions do not establish facts but rather are themselves established when their potential is realized. Empirically, this involves two points. First, paying attention not only to actual entities but also their processes of becoming and acknowledging that such processes are continual. Second, to get at the substantive relations between an abstract object, such as obesity, and its actualisations entails examining concrete arrangements. The notion of proposition indicates how prototypes necessitate the possibility of an actual world, how they can become differently and their capacity to do so irrespective of a particular actualisation. Furthermore, included in this becoming is the analyst and designers who, from the outset, are uncertain of what is relevant since what it means to 'know' is open and indexical to other conditions.

Thinking prototypes as event thereby implies an ethical dimension in so far as it involves the way in which problems as propositions are articulated and how actors are positioned within the problem space (Fraser, 2010). ${ }^{9}$ Now, this counts for both understanding the way in obesity and sociotechnical solutions for obesity are framed and how such framing engenders and positions those actors and practices, such as routine exercise, test users and future users, directly implicated in prototyping. It also, however, provides a reflexive caution to the ethical application of event thinking in the social sciences, such as this case study. This is not so much a question of how to account for my own ethnographic intervention but how to acknowledge my becoming as an ethnographer-user.

In sum, the implications of the notion of event in relation to prototyping a new medicotechnological reality to intervene in the risk, onset or management of obesity include: specifying the technical practices specific to prototyping, tracing the particular compositions and kinds of healthcare collectives that arise therein; discerning the positioning of actors generated by prototyping and the ensuing cosmopolitics of such positionings; locating the differences to a before and after that entail; indicating the identifiable overflows or excesses to the scope of a prototype event as well as; bearing ethnographic witness to the becoming or coindividuation of the case, including ones own emplacement. What this builds to, drawing on Fraser (2006, p. 132), is a view of prototyping as inventive "problem-making" rather than "problem-solving". This means analysing the activities of a design team as they go about reasoning and assembling as a case where the problem of obesity is variously situated in relation to a process that mobilises and transforms heterogeneous entities, including government and inter-governmental instruments, distal and proximal users as well as the constituent technologies. 


\section{The Scene}

In 1999 the corporation, a leading microprocessor manufacturer where I conducted the fieldwork on which this paper draws, became active in the development of healthcare technology and related information services. According to publicity, the corporation's engagement with healthcare came about as a consequence of research conducted by in-house industrial ethnographers who identified the 'needs' of providers and patients alike, thus opening up the prospect of healthcare as a potential microprocessor market. Subsequently, healthcare became a major preoccupation of the corporation, where considerable resources were deployed to support of a wide range of innovation, technical standardization and marketing activities to establish itself as a global provider of IT systems for healthcare and related services. Notably, this included the institution of a healthcare division tasked with developing information systems for healthcare providers, health insurance companies and government agencies, expert information systems for pharmaceutical and biotechnology companies, communication and telemedicine technologies to facilitate remote healthcare and patient care information systems for healthcare practitioners.

Within this context, the design group, working under the principles of user-centered design was engaged with members of one of the corporation's many technical research laboratories to design and develop a health and fitness prototype conceived to intervene in the increasing global prevalence of obesity. Here, the task of the designers group was to assist in the visual and formal design of the device, mobilising corporate expertise that the research laboratory believed the project required. To better grasp the eventfulness of the case, I employ the heuristic distinction between distal and proximal to differentiate between users that operate in the present but occupy different temporal moments in relation to the prototype.

\section{The Problem Space: Obesity, Inventive Risk Discourse and Distal Users}

Now, the health and fitness prototype - a mobile phone based exercise management system was envisaged as a wearable technology to address the causes, onset and management of obesity. That is to say, the device was conceived as a technology to allow patients suffering or at risk from the disease to self-manage the condition. The purpose of the device was to encourage people to carry out and reflect upon their daily exercise with the aid of a bodyworn information system that made each and every footstep accountable as exercise. The reasoning underwriting the development of the device was to motivate and support people at risk or suffering from obesity to carry out higher than normal levels of daily physical activity. Here, the key insight of the researchers was that any routine activity could count as exercise and that pervasive ubicomp technologies provided the means to render such activities visible and manageable. ${ }^{10}$ Thus, the researchers set out to design a wearable technology to support 
individual and groups of people to carry out both formal (structured) and informal (opportunistic) exercise during the course of a day. To this end, the researchers devised a system that underwent at least two iterative stages of development: a rapidly developed proof of concept including a commercially available mobile phone running a journaling application and an off-the-shelf pedometer, which required users to manually input their step count and subsequently; a more 'developed' prototype where a novel sensing device replaced the pedometer in order to automate the quantification of step counts. In both cases, the software, developed by the researchers, encouraged users to self-administer and reflect on daily exercise programs.

The broader rationale framing the development of the prototype, enacted in conference proceedings, corporate presentations, meetings and sites of publicity, placed the device in relation to U.S. and global fears associated with the increasing prevalence of obesity. Invoking reports by the U.S Surgeon General, the U.S. Centers for Disease Control and Prevention $(\mathrm{CDC})$ and the WHO, the designers mobilised institutional fears about the exponential growth of the disease to construct two health prospects: a future with and a future without their intervention. Drawing on official statistics, the researchers claimed "over one billion overweight adults (300+ million of whom are obese)" and "overweight and obesity in the U.S. are an epidemic, affecting over sixty percent of adults". The researchers also pointed to the economic implications of obesity, quoting over $\$ 100$ Billion USD in costs associated with the treatment of the disease. Thus, in bifurcating global health futures the researchers mobilised government and intergovernmental health agencies and statistical forecasting and their associated discursive practices of risk to portray an ungovernable pandemic future. The alternate, harnessing the expert recommendations of the U.S. Surgeon General and the CDC, depicted a future where the adiposity amongst a population could be controlled through individuals' daily exercise regimes supported by a body-worn information technology.

Drawing on Beck's (1992) notion of risk, the rationale deployed by the researchers can be understood as an example of 'inventive risk discourse' as applied in design, where a dialectic between future sociotechnical threats and opportunities are rhetorically played out in order to warrant further inventive practices. Here, the term inventive risk discourse characterises the articulation of a calculus of risk set against prospective opportunities in which novel markets and contexts of use are rendered the object of action in the present. ${ }^{11}$ In constructing the problem space of obesity through the medium of inventive risk discourse, the researchers delineate two possible health vectors each with its own 'user' population: future users monitoring and managing the disease and pathological future non-users embodying an economic burden. One key feature of inventive risk discourse is the speculative alignment made between individual practices and population management. Following Foucault (1998, p. 
139) the discursive practices of the designers contain aspects of biopower which serve to align the researchers' agenda of enhancing individuals' routine activities, the corporations strategic orientation to healthcare markets and government and intergovernmental instruments for population management. In other words, the researchers' rationale operates along two lines simultaneously where individuals are disciplined and optimised as part of government regulation. If inventive risk discourse works to articulate users and ubicomp technologies with the policies and techniques of government, then the sociomaterial prototyping practices of the designers, examined next, can be likened to the doing of anatomo-politics in efforts to configure bodies and technologies to the terrain of political practices. ${ }^{12}$ Nonetheless, given the 'inventive' nature of the researchers' discursive practices, these envisioning practices are irreducible to the biopolitical. ${ }^{13}$ There is more going on, such as the emergence of the designers' entrepreneurial efforts to construct new spaces for microprocessor applications and the implications for the discipline of Human-computer Interaction (HCI) and ubicomp.

The event of inventive risk discourse in this case served to transform the designers' translation of the multiple expectations into the conditions warranting the design of a concrete system by way of the prototype. Thus, the distal users emerged out of the interplay between statistical regimes of disease control and population management, the corporate drive to shape and colonise healthcare markets and the climates of possibility associated with ubicomp to intervene on disease by way individuals' everyday lifestyles. Consequently, obesity becomes a bifurcation of expectations. On the one hand obesity is actualised as a statistical entity in an ongoing and uncontrollable epidemic vector, whilst, on the other, it is actualised as an embodied and calculable disease pervading the practicalities of individuals' everyday physical activity, which in turn renders the body as a site for the explicit computational maintenance of body mass. Needless to say, the latter vision becomes as a proviso of the designers' work.

\section{The Device: Occasioning Proximal Users}

As previously mentioned, the development of the health and fitness prototype included two clearly defined and iterative phases. In the first, the researchers employed a market research company to recruit three groups of women between the ages of twenty-eight and forty-two as test users in order to evaluate the handset-software-pedometer prototype configuration. The test users were chosen by way of a screening process which included the U.S. Department of Health and Human Services questionnaire, derived from the 'spiral model of behaviour change' developed by the behavioural scientists Prochaska et al. (1992). Here, the success of the trial was determined by using the body mass index (BMI) to determine deviation in body weight amongst the trial participants. Curiously, in the context of developing a device to address obesity set-up, only two of the trial participants were categorised as overweight whilst the other were mostly normal or underweight. To work around this inconsistency, between 
preventing and treating obesity, and the actual BMI of the trial participants, the researchers extended the scope of their rationale from preventing and managing weight gain to simply encouraging physical fitness. Four points are of interest here. First, only those applicants viewed as 'purposely' capable of behaviour change were chosen to take part. Second, in drawing on the work of Prochaska et al. the researchers figured the test-users as cognitively equivalent to persons with substance dependency, such as smokers, and capable of selfcessation. Third, the deployment of the screening process, including the BMI formula, provided a means of articulating the bodies and behaviour of individual test-users with the rationale for the prototype. In other words, the techniques of user-involvement deployed by the designers worked, somewhat unsuccessfully, to connect up inventive risk discourse with the user's emergent embodied and cognitive capacities. At the end of the field trial, and based on the qualitative feedback produced during interviews with the test-users, the researchers concluded that the in-situ context of activity - where and how a footstep was achieved - had to be made visible and accountable in order to provide a system fit for managing routine exercise. Lastly, the users summoned in the context of the trial didn't fully match the definition of users where obesity is actualised and that the device claims to be aimed at. The users became actors that might bring about more successful results and there was little attempt to engage with the complex reality of an actual obese user. Here, obesity equates with the presence or lack of exercise.

The principle feature of the second phase of the development of the health and fitness prototype was the replacement of the pedometer with a novel activity sensing 'platform', also under development in the research laboratory. ${ }^{14}$ The researchers viewed the incorporation of the sensing platform as a means to address the issue of identifying the context of a footstep, or in the language of the researchers, the 'in-situ' reality of a footstep. Whereas the pedometer was incapable of automatically identifying the effort of a particular footstep, such as walking up an incline or stairs, the sensing platform promised to automate activity recognition. Combining multiple sensing capabilities or 'modes', including but not limited to barometric pressure, temperature, humidity, acceleration and footfall, and artificial intelligence routines to identify 'ground truth' the sensor platform sought to redistribute activity recognition from the user to the prototype. Crucially, the sensing platform combined these sensing capabilities with wireless data communication and a rechargeable lithium polymer battery in a 'wearable' form. Thus, the designers could continue in their efforts to develop a body-worn device to aid weight management.

Needless to say, the development of the novel sensing platform also included the involvement of users. One ostensible rationale of the software and hardware engineers developing the sensing platform was to facilitate the automation of future healthcare practices such as patient 
observation, thus circumventing the reliance on 'expensive' expert medical staff or 'unreliable' self-reporting patients. To do so, the engineers conducted two tests; each enrolling graduate students of a computer science department affiliated with the research laboratory, in order to verify the actual environment in which the sensor platform was producing data. In the first test, students were equipped with notebooks and video cameras as well as preliminary sensor kits and were asked to conduct various indoor and outdoor activities including, but not limited to, sitting, standing, walking, using stairs and elevators as well as brushing teeth. In the second, a human observer accompanied each student, noting down the location and type of physical activity in a PDA. The tests, carried out over a number of weeks and totalling 40 hours, produced a dataset including sensor readings annotated with records of actual location and type of activity. Equipped with this data set, the engineers then employed machine-learning techniques to produce a software algorithm that could match live data output against predetermined patterns, or signatures, of physical activity. The engineers were, as a consequence, confident that the sensor platform exhibited a minimum of $90 \%$ accuracy and that this would not be affected by a larger sample, with the proviso that further tests were to be conducted across a wider variation of body types, ages and settings to verify the scaling to a population.

With such examples of proximal users, I have sketched out how the designers enrolled embodied users in the present to construct iterations of a technology to address different aspects of obesity as a problem space for the design of information technology, broadly put. As Brown and Webster point out (2004, p. 83), new medical technologies of body maintenance have a propensity to integrate the opposition between the individual and the collective. The co-becoming of overweight users and the prototype under the auspices of obesity as an inventive problem can also be seen to actualise this tension, and embody the disease, in various ways. The first example, concerning the trial users, shows how obesity was defined anew as a gendered condition that could be acted upon by women cognitively capable of observing and reporting their routine footsteps with the aid of the pedometer and thus intervening on their body mass. The inadvertent shift of scope from obesity to physical fitness further fixed obesity as a condition also immanent to healthy female bodies and as a virtual presence in physical exercise. The second example of proximal users provides yet another definition of obesity as an embodied becoming. As described above, this featured a redistribution of physical accounting practices from unreliable humans to the sensor platform. This reallocation became as a consequence of the application of machine learning, combining graduate students, multiple recording technologies and prototype sensor platforms, where the empirical reality of the students' situated tasks were rendered as computational patterns and factualised as applicable, with $90 \%$ confidence, to the routine physical activities of a population. Again, obesity gains definition as an embodied presence in the routine physical 
activities of people enhanced with a novel, wearable sensing and reporting system. However, in this case the delegation of accounting practices to the system absolves the user of continual reporting duties and in doing so implicates all routine activities, including, say, brushing teeth and vacuuming as obese related. The achievement of prototyping practices here, is to spread the disease across all practices of all populations, with $90 \%$ confidence.

Finally, in discussing proximal users, I turn to illustrate enactments of prototyping that acknowledge the designers as 'users' of the health and fitness device. In so doing I show how prototyping served to occasion the accountability of the designers in relation to their workplace and disciplinary commitments. The first concerns a subtle empirical variation where, during the transition from the first to the second phase, the designers renamed the project with a compound of the terms 'ubiquitous' and 'exercise', expressing the emerging relevance of the device and their interests to the disciplinary agenda of ubicomp. The designers further cemented this by reporting on the device's potential methodological application, within the discipline of HCI, as an instrument with which to evaluate users' situated activity more generally. The second illustration transpired during the corporation's annual research forum, soon after the second phase of development. It was at this meeting that the designers exhibited the device alongside other on-going projects being developed in the corporation's international network of research centers. Next to the designers, a colleague at another stall dedicated to communicating the sensing platform, presented the devices' relevance to various future applications. Thus, presented side-by-side, the health and fitness prototype and the sensing platform delineated one application, whilst at the same time resourcing other, and in some cases very different, applications. On the one hand the sensing platform was subsumed as an intervention into obesity, whilst, on the other, the sensing platform included obesity as just one potential application alongside situated surveying, logistical and other industrial applications, the detection of Chronic Obstructive Pulmonary Disease as well as an enhancement to physical fitness activities. In short, each application proposes new collectives and temporalities without compromising one another.

The role of designer-users in this case points to aspects of overspill and indeterminacy occasioned during prototyping: aspects, which challenge the nature of the project and bring in new opportunities, new realities, not least the shift in definition from disease prevention and management to exercise in general as occurred during phase one. That is to say, aspects of prototyping where changes in order brought on by the project's eventfulness demonstrate the vital importance of indeterminacy to design practice. ${ }^{15}$ As such, the concept of event illuminates instances where prototyping practices exceed instrumental user-technology outcomes. The change in project title suggests the designers' use of the prototype also defines obesity anew, as topic in relation to workplace and disciplinary commitments as well as 
economic opportunity. Occasioned in the research forum, the health and fitness prototype is re-articulated as a coherent project reporting on an engagement between the research resources of the corporation and a prospective microprocessor market in the form of a particular use case. Alongside this, the demonstration of the sensing platform as an independent project enacts redefinitions of computationally enhanced obesity and the immanent reality of other computationally sensed practices. Doubtless there are other overspills, other actors, entities, and prehensions I have not discerned or appreciated. Regardless, the slight shifts, changes in specification or name and mode of demonstration suggest an ongoing openness for the prototype or aspects of the prototype, to enter into new becomings.

In sum, the multiple instances of user-prototype co-becomings I have presented point to how obesity emerged in empirical variation, or to use the vocabulary of the event, how the disease variously concretised through prototyping practices. What we call 'obesity' concretely emerges and is defined anew through the multiple displacements that are enacted during prototyping and embodied in the material device. The implication of this insight is that obesity is a disease that is never abstract; it is always concrete. There is no abstract 'obesity' simply because it is constantly being actualised as an event, whether through discursive envisioning or hands-on prototyping, obesity is always being specified as this particular form of obesity. Now, sometimes such events endure and might be seen as vectors (Danholt, 2005), or, perhaps events might be resourced by materialisations such as this paper, conditioning against occurrences from perishing, such as the demo at the research forum. Mol (1999, p. 83) makes the point multiplicity may bring about clashes of realities, for example different versions of a disease such obesity, they can also hang together, co-exist and even rely on one another. Event thinking, on the other hand, is predisposed to what Whitehead called 'abstractions' or the 'empirically felt variations' (Stengers, 2008, p. 96) of obesity brought about by the practices of designers.

\section{Conclusion}

In this article I have presented a view of prototyping in design as a socio-material process of becoming that articulated and engaged the problem space of obesity, framed as an acute global public health crisis ameliorated via a body-worn exercise management technology. In doing so I have taken up the notion of event to understand the multiple user-technology concrescences occasioned by local design activities through which actual obesity is continually redefined. As such, this case demonstrates how prototypes support the sociomaterial exploration of multiple futures, not least what might be seen as the prospective efforts of the designers to interface the biopolitical efforts of public health agencies with the technological disciplining of peoples everyday activities who are at risk or suffering from obesity. To 
understand the multiplicity of becoming I have distinguished between distal and proximate users. Distal users, I have argued, count as occupants of a future terrain in which the prototype was imaginatively located. As such, distal users served in the linking up of the designers' emergent and contingent interests with corporate agendas and government healthcare instruments. Proximal users illustrate how the prototype worked as part of the reification of obesity to meet the practical demands of designing a new healthcare technology as well as resource the commercial and disciplinary possibilities of activity sensing. In practice, the prototype occasioned a multiplicity of engagements between designers and users that functioned to bring together numerous alignments including, but not limited to: designers' visions and research agendas with government and inter-governmental policy and corporate strategy; the formatting of bodies and technology; the connections between technical innovation and product development, as between the activities of the designers and engineers, in relation to wider research and development in the form of publicity.

This paper, then, stands as a rough cosmopolitical sketch of design as enacted in prototyping practices, where the production of durable prototypes positioned health care agencies, the corporation, prospective microprocessor markets, populations and bodies in relation to an alarmist epidemic vector. In other words, the paper discerns an emergent cosmos of human and non-humans that become together during prototyping to enact concrete variants of obesity. The multiple becomings I have described, worked to play these off against the designers' emerging interest in new technological applications whilst neglecting substantial scientific and cultural evidence to alternative and much less dramatic futures of being overweight.

\section{Acknowledgments}

I would like to thank Mike Michael and Michael Halewood for their insightful comments and clarifications on earlier drafts. 


\section{Notes}

${ }^{1}$ See (Monaghan et al., 2010) for a typology of 'obesity entrepreneurs'.

2 There is a rich tradition of user-involvement in technological design with multiple genealogies and approaches (e.g. Asaro, 2000).

${ }^{3}$ Notably, this view of prototyping, as the tension between supporting existing practices and bring new practices into being, is echoed by Ehn (1988, pp. 128-129) and Mogensen (1992, p. 1).

${ }^{4}$ Incidentally, the notion of 'vector' recasts the normative temporalities associated with the dynamics and patterning of technological change as it avoids the 'natural' and 'self-sustaining' tropes of Newtonian mechanics (Mackenzie, 1990, p. 168).

${ }^{5}$ See the edited volume (Brown et al., 2000) for a collection of sociological studies taking sociotechnical futures as an object of empirical analysis. More specifically, Michael's (2000) exploration of the performativity of future representations bears relation to this paper. See (Wilkie and Michael, 2009) for a discussion of how the figure of the user is deployed to enact policy futures.

${ }^{6}$ See (Michael, 2011) for an exploration of 'Speculative Design' practices and engagement processes where the figure of the 'idiot' is employed to understand how design practice disrupts sociological accounts of science and society engagement processes.

${ }^{7}$ Cf. (Deleuze, 2001 [1988], pp. 76-82).

${ }^{8}$ Although principally concerned with the scientific event and the singularity of scientific practice, Stengers' also discusses the philosophical event (2005b, p. 148), implying the eventfulness and distinctiveness (and cosmopolitics) of other disciplines and fields such as social science (Brown, 2010, p. 117 ) and design.

9 This point echoes Latour's (2004, p. 83) understanding of propositions as collectives in the process of becoming who's admission into political reality depends on how well (semiotically and materially) articulated new actors are. However, as Fraser (2010, p. 70) contends, Latour's version concerns an exteriority of excluded entities that can be apprehended, whereas for Whitehead (and Stengers) potential includes things which cannot be found or an unavailable for inclusion.

10 Ubiquitous computing, coined by Weiser (1991, p. 94), is a vision of computing where microprocessors and calculation are seen as an embedded feature of everyday objects and activities.

${ }^{11}$ Beck (1999, p. 49) alerts us to the inventive and economic capacities of risk promoting the "exploration of new worlds and new markets". In doing so he draws upon Giddens' (1999, p. 8) recognition of risk as a productive and active "energizing principle".

12 See (Wright and Harwood, 2009) for an in-depth discussion of the biopolitics of obesity.

${ }^{13}$ Deleuze and Guattari (1988, p. 531), in contrast to Foucault, argue that biopolitics cannot be reduced to stabilised arrangements of power and resistance but also modes creativity and the repatterning of relations. 
14 'Platform' here refers to an underlying configuration of hardware and software, including firmware instructions, which acts as a basis for the development of a particular application, such as the sensing of routine exercise.

15 The eventfulness of prototyping in design as a practice that incorporates indeterminacy evokes discussions concerning the ability of telecare systems to cope with and respond to unforeseen events and deliver immediate care to stricken users (López and Domènech, 2008) as well as conceptual figures as facilitators of potential and change such as the 'blank figure' (Hetherington and Lee, 2000), the parasite (Serres, 2007) and the idiot (Deleuze and Guattari, 2011, Stengers, 2005a), which, incidentally, Michael has employed (2011) to characterize the eventfulness of designerly interventions into public engagement with science. 


\section{References}

Adams, V., Murphy, M. \& Clarke, A. E. (2009) Anticipation: Technoscience, Life, Affect, Temporality. Subjectivity, vol. 28, no. 1, pp. 246-265.

Akrich, M. (1992a) Beyond Social Construction of Technology: The Shaping of People and Things in the Innovation Process. In: Dierkes, M. \& Hoffman, U. (eds.) New Technology at the Outset: Social Forces in the Shaping of Technological Innovations. Frankfurt \& New York: Campus Verlag.

Akrich, M. (1992b) The De-Scription of Technical Objects. In: Bijker, W. \& Law, J. (eds.) Shaping Technology/Building Society: Studies in Sociotechnical Change. Cambridge, Mass.: MIT.

Asaro, P. M. (2000) Transforming Society by Transforming Technology: The Science and Politics of Participatory Design. Accounting, Management and Information Studies, vol. 10, no. 4, pp. 257-290.

Beck, U. (1992) Risk Society: Towards a New Modernity, London, Sage.

Beck, U. (1999) World Risk Society, Cambridge, Polity.

Berg, M. (1998) The Politics of Technology: On Bringing Social Theory into Technological Design. Science, Technology, \& Human Values, vol. 23, no. 4, pp. 456-490.

Bødker, S. \& Grønbæk, K. (1991) Design in Action: From Prototyping by Demostration to Cooperative Prototyping. In: Greenbaum, J. M. \& Kyng, M. (eds.) Design at Work : Cooperative Design of Computer Systems. Hillsdale, N.J.: L. Erlbaum Associates.

Brown, N., Rappert, B. \& Webster, A. (eds.) (2000) Contested Futures: A Sociology of Prospective Techno-Science, Aldershot: Ashgate.

Brown, N. \& Webster, A. (2004) New Medical Technologies and Society: Reordering Life, Cambridge, Polity.

Brown, S. D. (2010) Between the Planes: Deleuze and Social Science. In: Jense, C. B. \& Rödje, K. (eds.) Deleuzian Intersections: Science, Technology and Anthropology. New York; Oxford: Berghahn Books.

Butland, B., Jebb, S., Kopelman, P., Mcpherson, K., Thomas, S., Mardell, J. \& Parry, V. (2007) Foresight Tackling Obesities: Future Choices - Project Report. 2nd ed. London: Government Office for Science.

Callon, M. (1986) The Sociology of an Actor-Network: The Case of the Electric Vehicle. Mapping the Dynamics of Science and Technology. London: Macmillan.

Campos, P., Saguy, A., Ernsberger, P., Oliver, E. \& Gaesser, G. (2006) The Epidemiology of Overweight and Obesity: Public Health Crisis or Moral Panic? International Journal of Epidemiology, vol. 35, no. 1, pp. 55-60.

Danholt, P. (2005) Prototypes as Performative, Aarhus, Denmark, ACM Press.

De Laat, B. (2000) Scripts for the Future: Using Innovation Studies to Design Foresight Tools. In: Brown, N., Rappert, B. \& Webster, A. (eds.) Contested Futures: A Sociology of Prospective Techno-Science. Aldershot: Ashgate.

Deleuze, G. (2001 [1988]) The Fold: Leibniz and the Baroque, Minneapolis, University of Minnesota Press. 
Deleuze, G. \& Guattari, F. (1988) A Thousand Plateaus: Capitalism and Schizophrenia, London, Athlone.

Deleuze, G. \& Guattari, F. (2011) What Is Philosophy?, London; New York, Verso.

Ehn, P. (1988) Work-Oriented Design of Computer Artifacts, Stockholm, Arbetslivscentrum.

Ehn, P. \& Kyng, M. (1991) Cardboard Computers: Mocking It up or Hands on the Future. In: Greenbaum, J. M. \& Kyng, M. (eds.) Design at Work: Cooperative Design of Computer Systems. Hillsdale, N.J.: L. Erlbaum Associates.

Foucault, M. (1998) The History of Sexuality: Volume One, London, Penguin.

Fraser, M. (2006) Event. Theory, Culture \& Society, vol. 23, no., pp. 129-132.

Fraser, M. (2010) Facts, Ethics and Event. In: Jense, C. B. \& Rödje, K. (eds.) Deleuzian Intersections: Science, Technology and Anthropology. New York; Oxford: Berghahn Books.

Garfinkel, H. (1967) Studies in Ethnomethodology, Cambridge, Polity, 1984.

Garrety, K. \& Badham, R. (2004) User-Centered Design and the Normative Politics of Technology. Science Technology Human Values, vol. 29, no. 2, pp. 191-212.

Giddens, A. (1999) Risk and Responsibility. Modern Law Review, vol. 62, no. 1, pp. 1-10.

Hetherington, K. \& Lee, N. (2000) Social Order and the Blank Figure. Environment and Planning D, vol. 18, no. 2, pp. 169-184.

Kline, R. \& Pinch, T. (1996) Users as Agents of Technological Change: The Social Construction of the Automobile in the Rural United States. Technology and Culture, vol. 37, no. 4, pp. 763-795.

Latour, B. (2004) Politics of Nature: How to Bring the Sciences into Democracy, Cambridge, Mass.; London, Harvard University Press.

Law, J. \& Callon, M. (1992) The Life and Death of an Aircraft: A Network Analysis of Technical Change. In: Bijker Wiebe, E. \& Law, J. (eds.) Shaping Technology/Buiding Society. Cambridge, Massachusetts; London, England: MIT Press.

López, D. \& Domènech, M. (2008) On Inscriptions and Ex-Inscriptions: The Production of Immediacy in a Home Telecare Service. Environment and planning. D, Society and space, vol. 26, no. 4, pp. 663.

Mackenzie, A. (2005) Problematising the Technological: The Object as Event? Social Epistemology, vol. 19, no. 4, pp. 381-399.

Mackenzie, D. A. (1990) Inventing Accuracy: A Historical Sociology of Nuclear Missile Guidance, Cambridge, Mass. ; London, MIT Press.

Michael, M. (2000) Futures of the Present: From Performativity to Prehension. In: Brown, N., Rappert, B. \& Webster, A. (eds.) Contested Futures: A Sociology of Prospective TechnoScience. Aldershot: Ashgate.

Michael, M. (2011) "What Are We Busy Doing?": Engaging the Idiot. Science, Technology \& Human Values, vol., no., pp.

Mogensen, P. (1992) Towards a Provotyping Approach in Systems Development. Scandinavian Journal of Information Systems, vol. 4, no., pp. 31-53. 
Mol, A. (1999) Ontological Politics. A Word and Some Questions. In: Law, J. \& Hassard, J. (eds.) Actor Network Theory and After. Oxford; Malden, Massachusetts: Blackwell Publishers/The Sociological Review.

Monaghan, L. F., Hollands, R. \& Pritchard, G. (2010) Obestity Epidemic Entrepreneurs: Types, Practices and Interests. Body and Society, vol. 16, no. 2, pp. 37-71.

Oudshoorn, N. \& Pinch, T. J. (2003) Introduction: How Users and Non-Users Matter. In: Oudshoorn, N. \& Pinch, T. J. (eds.) How Users Matter: The Co-Construction of Users and Technologies. Cambridge, Mass.: MIT Press.

Prochaska, J., Diclemente, C. \& Norcross, J. (1992) In Search of How People Change: Applications to Addictive Behavior. American Psychologist, vol. 47, no. 9, pp. 1102-1114.

Saguy, A. C. \& Almeling, R. (2008) Fat in the Fire? Science, the News Media, and the 'Obesity Epidemic'. Sociological Forum, vol. 23, no. 1, pp. 53-83.

Saguy, A. C. \& Riley, K. W. (2005) Weighing Both Sides: Morality, Mortality, and Framing Contests over Obesity. Journal of health politics, policy and law, vol. 30, no. 5, pp. 869923.

Serres, M. (2007) The Parasite, Minneapolis, London, University of Minnesota Press.

Star, S. L. \& Griesemer, J. R. (1989) Institutional Ecology, 'Translations' and Boundary Objects: Amateurs and Professionals in Berkeley's Museum of Vertebrate Zoology, 1907-39. Social Studies of Science, vol. 19, no. 3, pp. 387-420.

Stengers, I. (2000) The Invention of Modern Science, Minneapolis ; London, University of Minnesota Press.

Stengers, I. (2005a) The Cosmopolitical Proposal. In: Latour, B. \& Weibel, P. (eds.) Making Things Public. Cambridge, MA: MIT Press.

Stengers, I. (2005b) Events and Histories of Knowledge. Review (Fernand Braudel Center), vol. 28, no. 2, pp. 143-159.

Stengers, I. (2008) A Constructivist Reading of Process and Reality. Theory, Culture \& Society, vol. 25, no. 4, pp. 91-110.

Suchman, L., Trigg, R. \& Blomberg, J. (2002) Working Artefacts: Ethnomethods of the Prototype. British Journal of Sociology, vol. 53, no. 2, pp. 163-179.

U.S. Department of Health and Human Services (2000) Healthy People 2010: Tracking Healthy People 2010, U.S. Department of Health and Human Services.

U.S. Department of Health and Human Services (2001) The Surgeon General's Call to Action to Prevent and Decrease Overweight and Obesity. In: U.S. Dept. Of Health and Human Services (ed.). Rockville, MD: U.S. Department of Health and Human Services, Public Health Service, Office of the Surgeon General,.

Weiser, M. (1991) The Computer for the 21 st Century. Scientific American, vol. 256, no. 3, pp. 94-104.

Whitehead, A. N. (1978) Process and Reality: An Essay in Cosmology. (Gifford Lectures of 19278). New York, The Free Press.

Wilkie, A. (2010) User Assemblages in Design: An Ethnographic Study. Ph.D, Goldsmiths, University of London. 
Wilkie, A. \& Michael, M. (2009) Expectation and Mobilisation: Enacting Future Users. Science Technology Human Values, vol. 34, no. 4, pp. 502-522.

Woolgar, S. (1991) Configuring the User: The Case of Usability Trials. In: Law, J. (ed.) Sociology of Monsters: Essays on Power, Technology and Domination. London: Routledge.

World Health Organisation (2000) Obesity: Preventing and Managing the Global Epidemic. Geneva: World Health Organization.

Wright, J. \& Harwood, V. (eds.) (2009) Biopolitics and the 'Obesity Epidemic': Governing Bodies, New York; London: Routledge.

Wyatt, S. (2003) Non-Users Also Matter: The Construction of Users and Non-Users of the Internet. In: Oudshoorn, N. \& Pinch, T. J. (eds.) How Users Matter: The CoConstruction of Users and Technologies. Cambridge, Mass.: MIT. 